\title{
Portal da Amazônia: Uma Solução Sistêmica para o Controle de Ativos (Conteúdos) Acadêmicos
}

\author{
Alexandre Monassa ${ }^{1}$, Ewelton Y. C. Yoshidome ${ }^{1}$, Maurício R. de A. Souza ${ }^{1}$, \\ Paulo Rudolph ${ }^{1}$, Vitor P. Feitosa ${ }^{1}$, Wallace M. P. Lira ${ }^{1}$, Arnaldo C. Prado Junior ${ }^{1}$, \\ Sandro R. Bezerra Oliveira ${ }^{1}$ \\ ${ }^{1}$ Faculdade de Computação - Instituto de Ciências Exatas e Naturais (ICEN) - \\ Universidade Federal do Pará (UFPA), Rua Augusto Corrêa, 01, Belém -PA - Brasil

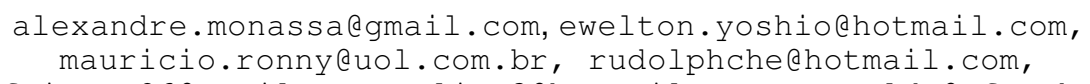

\begin{abstract}
Portal da Amazônia is a Web environment for gathering and publication of academic, scientific, cultural and artistic content about the Amazon region, representing a systemic solution to make use of these contents in a concise and validated way in three languages. In this paper it is presented the Portal da Amazonia (its workflow and functioning), discussing its development and considering new trends that can be applied to the product.

Resumo. O Portal da Amazônia é um ambiente Web para a concentração e publicação de conteúdo de cunho acadêmico, científico, cultural e artístico da região amazônica, representando uma solução sistêmica para a disponibilização desses conteúdos de forma concisa, validada e em três idiomas. Neste artigo é apresentado o Portal da Amazônia (seu fluxo, funcionamento), será discutido seu desenvolvimento e apresentadas novas tendências que podem ser aplicadas ao produto.
\end{abstract}

\section{Introdução}

O mundo vive um contexto de valorização da informação, cada vez mais se torna importante a disponibilização, em larga escala, da informação e igualmente importante é a dinamicidade da publicação. Sob esta visão, a informática se mostra uma ferramenta poderosa para atender essa demanda, na forma de sistemas de informação. Pode-se integrar rapidez, acessibilidade e gerenciamento [O'brien, 2004].

Tendo em vista as políticas de divulgação de informação e inserção da cultura da Amazônia no cenário mundial, a Universidade Federal do Pará (UFPA), ciente dessa demanda e de posse dos recursos acadêmicos e pedagógicos, se propôs a realizar, na forma de um projeto de pesquisa, o desenvolvimento de um Sistema de Informação que contemplasse a necessidade de concentrar e divulgar conhecimentos e ativos (conteúdos) sobre a região, o Portal da Amazônia [Lemos et al, 2006], cujos objetivos específicos serão discutidos ao longo deste trabalho.

Um Sistema de Informação (SI) é um sistema que objetiva armazenar, tratar e fornecer informações para apoiar processos e funções. Um SI é composto por pessoas, processos, informações e documentos, que formam um sub-sistema social, interligados por meios automatizados (redes de comunicação, computadores) [O'brien, 2004]. Sendo 
assim, o Portal da Amazônia foi projetado para ser um ambiente $W e b^{l}$ para visualização de conteúdos, que conta com toda uma estrutura para tratar a publicação destes, através de um sistema computacional, fornecendo os devidos recursos para que uma equipe possa trabalhar na edição, tradução, validação e publicação de forma sistêmica, o que será aprofundado em seções adiante.

O "Portal da Amazônia: navegando entre o rio e a floresta" nasceu em 2001, como um projeto aprovado pelo Conselho Nacional de Desenvolvimento Científico e Tecnológico (CNPQ), para revitalizar o Sistema de Informação Científica e Tecnológica da Amazônia (Informam). Encontra-se em sua segunda versão atualmente, envolvendo professores, técnicos e alunos da graduação, pós-graduação nas atividades de ensino, pesquisa e extensão. Conta, hoje, com: uma equipe de 17 (dezessete) integrantes, composta por: equipe de desenvolvimento, formada por graduandos, graduados e professor da Faculdade de Computação da Universidade Federal do Pará; e uma equipe de conteúdo, que compreende pessoal das áreas de Biblioteconomia, Letras, Artes e Jornalismo e a gerência do portal cujos integrantes são também da área de Biblioteconomia e Letras. O Portal da Amazônia constitui um laboratório em si mesmo, para o seu desenvolvimento.

Além desta seção introdutória, este artigo descreve as metodologias e técnicas de Engenharia de Software ${ }^{2}$ que foram adotadas no decorrer do desenvolvimento projeto. A Seção 2 apresenta de uma forma geral o projeto do Portal Amazônia. Na Seção 3 será especificado o fluxo de atividades modelado para gerenciar os conteúdos submetidos ao sistema. A Seção 4 representa em especificações técnicas, como se deu o desenvolvimento sistêmico do Portal. Na Seção 5 serão apontados alguns resultados, desafios e lições aprendidas ao longo do desenvolvimento do projeto. Finalmente a Seção 6 apresenta as considerações finais deste trabalho.

\section{O Portal}

O Portal da Amazônia, nascido de projetos integrados de ensino, pesquisa e extensão [Prado Junior, 2004, 2006], traz uma solução atualizada para o armazenamento e compartilhamento de conteúdos (produção científica, artística, cultural e acadêmica) relacionados à região Amazônica, disponível para a população acadêmica em geral. Trata-se de um sistema Web, trilíngüe (português, espanhol e inglês), extensível (seu desenvolvimento foi feito de forma a comportar novos tipos de conteúdos a serem adicionados conforme o amadurecimento do portal), onde é possível para qualquer pessoa visualizar conteúdos acadêmicos publicados e também publicar suas próprias produções. O Portal procura colaborar com o desenvolvimento da região através da gestão do conhecimento, da busca e recuperação da informação produzida sobre a Amazônia [Lemos et al, 2006].

O sistema está acessível por qualquer pessoa, desenvolvido utilizando procedimentos e metodologias de Engenharia de Software, com auxílio de softwares

\footnotetext{
${ }^{1}$ A World Wide Web (que em português significa, "Rede de alcance mundial"; também conhecida como Web e WWW) é um sistema de documentos em hipermídia que são interligados e executados na Internet.

2 É uma área do conhecimento da informática voltada para a especificação, desenvolvimento e manutenção de sistemas de software aplicando tecnologias e práticas de ciência da computação, gerência de projetos e outras disciplinas, objetivando organização, produtividade e qualidade.
} 
livres $^{3}$ tendo como objetivo o desenvolvimento de software próprio. Atualmente encontra-se em sua segunda versão, contendo uma quantidade de funcionalidades disponíveis parcialmente para os usuários como: funções referentes ao usuário (cadastro, edição e exclusão de funcionários) e a conteúdos (cadastro, edição, correção, visualização de conteúdos, entre outros).

Este sistema é extensível para adição de novos tipos de conteúdos, e atualmente conta com publicação de eventos, notícias, artigos, trabalhos científicos, receitas culinárias, livros e capítulos de livros. Sendo um portal com ênfase nos conteúdos que disponibiliza, deve garantir a qualidade de seus materiais publicados. Para isso, o sistema conta com um Fluxo de Atividades (representação gráfica que descreve o fluxo de trabalho de processos do negócio) que garante a integridade de conteúdos publicados, onde há papéis de usuário com responsabilidades bem definidas (Colaboradores, Editores, Gerentes, Tradutores, etc.) responsáveis pela produção, validação, edição, tradução e publicação dos conteúdos submetidos.

Sendo um sistema Web, o Portal da Amazônia é uma solução que procura ter acesso fácil e usabilidade intuitiva, isto é, ter facilidade no aprendizado do sistema por meio de diálogo simples e direto com o usuário, tornando-se uma prática fonte de pesquisas para assuntos relacionados à região amazônica. $\mathrm{O}$ sistema é dividido em três módulos funcionais, ou seja, grupos de tarefas que podem ser executados pelo usuário do sistema: Visualização de Conteúdos, Sistema de Gerência de Conteúdo e Sistema de Gerência de Usuários.

O Sistema de Gerência de Conteúdo consiste nas seguintes tarefas: submeter conteúdo, validar conteúdo, aprovar conteúdo, traduzir conteúdo, publicar conteúdo e administrar lixeira. Já o Sistema de Gerência de Usuário é formado por: cadastrar usuário, excluir usuário, alterar cadastro de usuário, excluir colaborador, solicitar exclusão de colaborador, alterar cadastro e solicitar cadastro.

\subsection{Objetivos}

O sistema Portal da Amazônia, objetiva ser uma solução de fácil utilização para concentrar e disponibilizar, para o público em geral, conteúdos relacionados a assuntos da região amazônica. Esta característica exige que o mesmo seja dotado de uma interface amigável, navegação simples e intuitiva, e deve ser fácil de utilizar, aprender e recordar: para os seus usuários, ser fácil de navegar e encontrar os conteúdos de seu interesse; para os seus colaboradores, permitir realizar o cadastramento de novos conteúdos com facilidade; e para os responsáveis pela manutenção do Portal, ser flexível a alterações (Jornalistas, Editores, Tradutores, etc.).

O sistema deve manter de forma íntegra os conteúdos cadastrados em seu banco de dados, montando um repositório de publicações sobre a Amazônia, não sendo tolerante a qualquer erro que possa ocasionar perda de dados. Deve disponibilizar, também, aos seus usuários, facilidade de encontrar os conteúdos desejados e estar disponível 24 (vinte e quatro) horas por dia em 7 (sete) dias por semana.

Como o Portal da Amazônia é destinado ao público geral, deve ser capaz de executar em máquinas com baixo potencial computacional (computadores com suas

\footnotetext{
${ }^{3}$ Segundo a definição criada pela Free Software Foundation, é qualquer programa de computador que pode ser usado, copiado, estudado, modificado e redistribuído sem nenhuma restrição [FSF, 2008].
} 
configurações de hardware, tais como: processador e memória que possuam capacidade reduzida) sem perder desempenho. Deve ter um baixo tempo de resposta (carregamento de páginas), para não causar desconforto aos usuários. Basicamente a máquina do usuário deve possuir, para tal finalidade, acesso à internet, navegadores IE (Internet Explorer) ou FireFox e uma resolução mínima para monitor de 800x600, para melhor visualização.

Adicionalmente, é importante enfatizar que a facilidade de manutenção é um dos requisitos-chave para o sistema. Isso decorre do fato de que o sistema é desenvolvido para o posterior acréscimo de novos conteúdos, devendo apresentar facilidade aos seus desenvolvedores para a realização de mudanças e ser estável o suficiente, de forma a apresentar baixos riscos frente a efeitos inesperados ocasionados por alterações.

\section{O Fluxo de Atividades}

Antes dos documentos submetidos para o Portal da Amazônia serem publicados, estes devem passar por atividades de avaliação desempenhadas por usuários específicos do sistema. Essas atividades têm como objetivo verificar a ocorrência de erros ou a presença de conteúdos inapropriados, além de disponibilizar os documentos submetidos nos idiomas inglês e espanhol antes de serem publicados, tendo como premissa a sua submissão no idioma português.

Como já tratado, o Portal da Amazônia é responsável por manter e publicar conteúdos acadêmicos coerentes e de qualidade, além de possuir estes conteúdos em três idiomas com o intuito de globalizar o portal e, não apenas restringi-lo à região amazônica. Desta forma, percebe-se a importância da especificação e da modelagem de um fluxo de atividades que melhor caracterize a manutenibilidade destes ativos informacionais. A Figura 1 representa diagramaticamente este fluxo, usando as notações da UML - Unified Modeling Language, e as Subseções 3.1 e 3.2 retratam um detalhamento dos objetos representados por este fluxo.

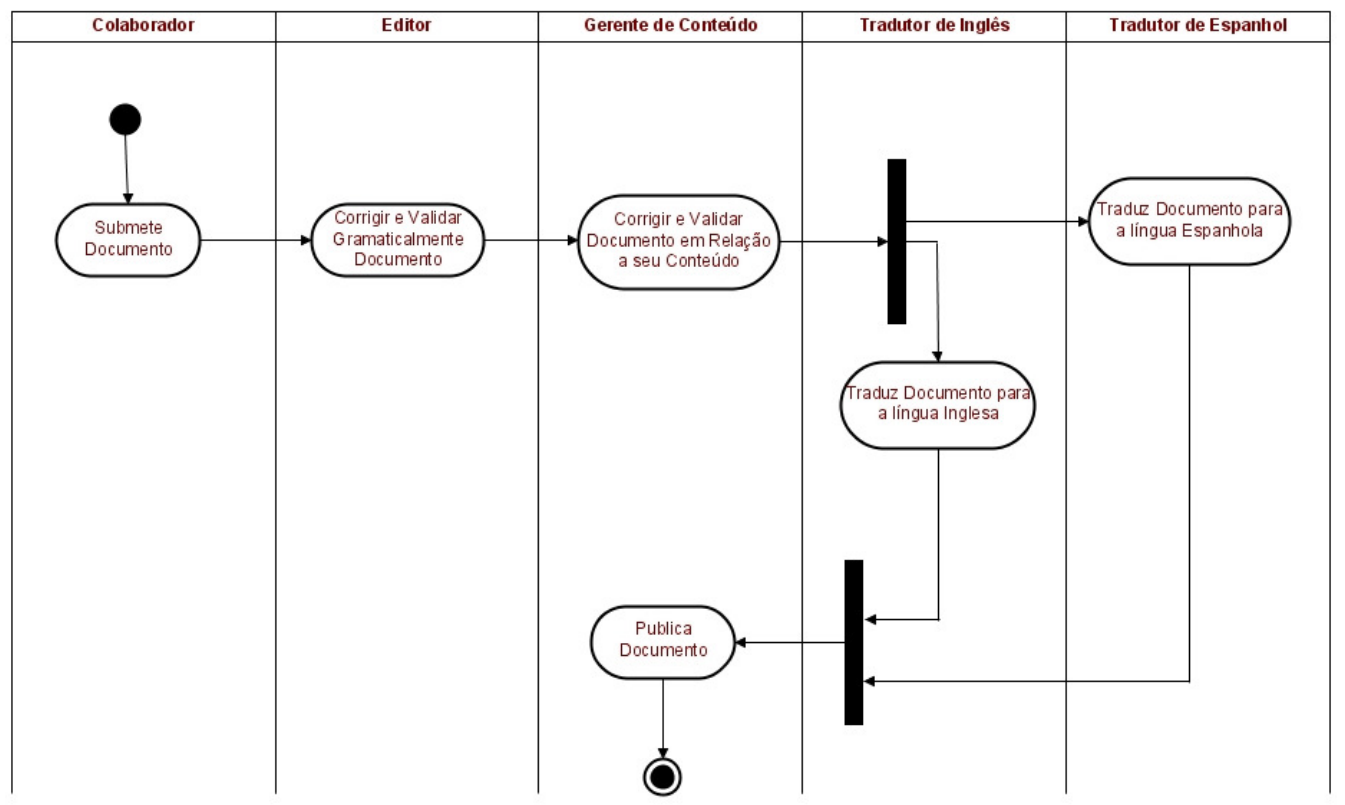

Figura 1. Fluxo de Atividades para o Controle de Documentos 


\subsection{Atores/Papéis}

O Portal da Amazônia se utiliza do conceito de atores/papéis para manter o fluxo de conteúdos que são submetidos. Um ator é desempenhado por um usuário que tem a habilidade de efetuar uma dada atividade no portal, como publicar e traduzir conteúdos. Atualmente, no Portal da Amazônia, existem 5 (cinco) tipos de atores diferentes:

- Colaborador: responsável pela submissão dos conteúdos no Portal da Amazônia, com exceção de notícia e evento que são submetidos apenas se o Colaborador também desempenhar o papel de Editor, Gerente de Conteúdo, Tradutor ou Administrador;

- Editor: responsável em verificar, principalmente, a possível existência de problemas de ortografia no documento submetido, além de possuir a autonomia de rejeitar documentos inapropriados (com conteúdo de pornografia, violência, etc). O Editor pode validar (aceitar), editar ou rejeitar um documento submetido;

- Gerente de Conteúdo: responsável em verificar se o conteúdo do documento é inapropriado ou se o conteúdo possui assunto relacionado à Amazônia. O Gerente de Conteúdo também verifica se o conteúdo do documento que está sendo avaliado é duplicado, ou seja, verifica se já existe algum documento similar cadastrado. O documento avaliado pelo Gerente de Conteúdo pode ser aprovado, editado ou rejeitado. Outra função do Gerente de Conteúdo é publicar os documentos no portal, isto é, disponibilizar para o público o acesso ao conteúdo;

- Tradutores de Espanhol e Inglês: responsáveis em traduzir o documento em seu respectivo idioma;

- Administrador: responsável pelo gerenciamento dos papéis de usuários, podendo adicionar ou remover permissão de Colaborador, Editor, Gerente de Conteúdo ou Tradutor, além de poder excluir usuários com a devida requisição.

Apesar dos papéis definidos, um usuário/recurso humano pode desempenhar mais de um papel ao mesmo tempo, de acordo com as suas responsabilidades e habilidades para as atividades do Portal.

\subsection{Descrição das Atividades}

Para garantir que o conteúdo publicado não seja disponível em apenas uma língua e que este não possuirá erros ou temas inadequados, os documentos no Portal da Amazônia passam por várias atividades definidas no fluxo da Figura 1. As atividades consistem em:

- Submissão: a fase de submissão é executada pelo colaborador e consiste em enviar o documento para o Portal da Amazônia;

- Validação: essa atividade, representada no fluxo pela atividade Corrigir $e$ Validar Gramaticalmente Documento, é desempenhada pelo Editor, quando o documento pode ser validado, enviado para correção ou reprovado;

- Aprovação: esta etapa é exercida pelo Gerente de Conteúdo após o documento ser validado, no qual poderá ser aprovado, enviado para correção ou rejeitado. 
Esta atividade é representada no fluxo pela atividade Corrigir e Validar Documento em Relação a ser Conteúdo;

- Tradução: depois que os documentos são aprovados, eles serão submetidos à tradução do seu conteúdo para o inglês e o espanhol. O documento não passará para a próxima etapa até ser traduzido para os dois idiomas. Esta atividade é representada no fluxo pelas atividades Traduz Documento para a língua Inglesa e Espanhola;

- Correção: esta atividade, representada no fluxo pelas atividades Corrigir $e$ Validar Gramaticalmente Documento e Corrigir e Validar Documento em Relação a seu Conteúdo, ocorrerá apenas se o Editor ou o Gerente de Conteúdo solicitar a correção do documento. Os documentos que são enviados para correção retornam para o autor do documento (Colaborador) contendo o motivo da solicitação de correção. O documento ficará retido nesta etapa até ser efetuada a correção. Depois da edição do documento por parte do Colaborador, o documento será submetido para ser reavaliado, reiniciando o fluxo a partir da etapa de validação;

- Publicação: após a disponibilização do documento em três idiomas (inglês, espanhol, português), o Gerente de Conteúdo decide a data em que o documento será publicado e, no caso de evento ou notícia com imagem, se o documento será publicado em destaque. Esta atividade é representada no fluxo pela atividade Publica Documento. Uma notícia ou um evento em destaque é aquele que aparecerá destacado na página inicial do portal, exibindo a sua imagem e título. Não existe um critério específico para publicação de um evento ou notícia em destaque, essa decisão é avaliada empiricamente pelo Gerente de Conteúdo.

\section{Desenvolvimento do Portal}

Esta seção retrata uma visão mais técnica das peculiaridades do processo usado para o desenvolvimento do Portal da Amazônia. Foram aplicadas ao Portal da Amazônia práticas de Engenharia de Software. Foi criado um processo de Engenharia de Software denominado Processo de Software Informam (PSI) [Barbosa, 2008], descrito na Subseção 4.1. Outra prática de Engenharia de Software trata da arquitetura implementada para o Portal da Amazônia, apresentada na Subseção 4.2.

Optou-se por usar como ferramenta de desenvolvimento Software Livre por ser de mais fácil obtenção, representando diminuição do orçamento, por cobrir satisfatoriamente as necessidades do projeto e por contar com um grande número de desenvolvedores atuantes nestas tecnologias. A implementação de projetos complexos baseados em Software Livre, o Linux incluso, dão respaldo a esta escolha. Os softwares de apoio e desenvolvimento utilizados são descritos na Subseção 4.3.

\subsection{Processo de Software Informam}

O alicerce da Engenharia de Software é a área de processo. Um processo de software é o arcabouço de procedimentos, ferramentas e artefatos que mantêm unidas as camadas de tecnologia e permite o desenvolvimento racional e oportuno de software [Pressman, 2005]. Tendo em vista este foi criado então o PSI. 
Este processo de software é baseado no Processo Unificado da Rational ${ }^{4}$ (RUP) e nas metodologias de desenvolvimento Ágil, eXtreme Programming ${ }^{5}$ (XP) e Agile Modeling ${ }^{6}$ (AM), adequando à realidade do ambiente do projeto. No processo estão descritos os fluxos de trabalho, que são seguidos pela equipe de desenvolvimento. Este fluxo é composto por atividades que abrangem desde o planejamento, seguindo pela gerência de projeto, implantação, análise, modelagem, implementação, teste e entrega [Barbosa, 2008].

O PSI não implementa nenhuma prática nova, consiste apenas de uma adaptação formal das características das metodologias, citadas anteriormente, interessantes à realidade de desenvolvimento do Portal da Amazônia. A Tabela 1 permite um melhor entendimento das características que perfazem a criação PSI.

Tabela 1. Características do PSI e suas conseqüências

\begin{tabular}{|l|l|}
\hline \multicolumn{1}{|c|}{ Característica } & \multicolumn{1}{|c|}{ Conseqüiência } \\
\hline $\begin{array}{l}\text { Incremental iterativo } \\
\text { [Pressman, 2005] }\end{array}$ & $\begin{array}{l}\text { Ao final de cada iteração, é gerada uma versão do } \\
\text { produto contendo modificações como, por exemplo, } \\
\text { novas funcionalidades, correções ou ajustes. }\end{array}$ \\
\hline $\begin{array}{l}\text { Utiliza a linguagem de } \\
\text { modelagem UML }\end{array}$ & $\begin{array}{l}\text { Os diagramas produzidos seguem um padrão consolidado } \\
\text { internacionalmente, facilitando a sua compreensão por } \\
\text { um leitor não envolvido em sua elaboração. }\end{array}$ \\
\hline $\begin{array}{l}\text { Maleável com relação aos } \\
\text { requisitos e ao processo }\end{array}$ & $\begin{array}{l}\text { Recomendado para equipes pequenas, com 4 a 12 } \\
\text { desenvolvedores para evitar caos no desenvolvimento. }\end{array}$ \\
\hline $\begin{array}{l}\text { Clientes fazem parte da } \\
\text { equipe de desenvolvimento }\end{array}$ & $\begin{array}{l}\text { Facilidade de comunicação com o cliente, mais } \\
\text { envolvido, possibilitando uma melhor coleta de } \\
\text { requisitos e avaliação da versão do produto ao final de } \\
\text { cada iteração. }\end{array}$ \\
\hline $\begin{array}{l}\text { Orientado a Casos de Uso } \\
\text { Necessidade de produção do artefato de desenvolvimento } \\
\text { Especificação de Casos de Uso, o documento básico para } \\
\text { a implementação do Portal da Amazônia. }\end{array}$ \\
\hline $\begin{array}{l}\text { Possui uma fila de Casos de } \\
\text { Uso Prioritários arranjados } \\
\text { em ordem decrescente de } \\
\text { importância }\end{array}$ & $\begin{array}{l}\text { Guia a implementação de requisitos mais importantes } \\
\text { primeiro em detrimento a requisitos menos importantes. }\end{array}$ \\
\hline
\end{tabular}

${ }^{4}$ É um processo de Engenharia de Software, que oferece uma abordagem baseada em disciplinas para atribuir tarefas e responsabilidades dentro de uma organização de desenvolvimento, cuja meta é garantir a produção de software de alta qualidade que atenda às necessidades dos usuários dentro de um cronograma e de um orçamento previsíveis [IBM, 2008].

${ }^{5}$ É uma metodologia de desenvolvimento de software, para ajudar a criar sistemas de melhor qualidade, que são produzidos em menos tempo e de forma mais econômica que o habitual, sendo alcançados através de um pequeno conjunto de valores, princípios e práticas, que diferem substancialmente da forma tradicional de se desenvolver software [Ambler, 2004].

${ }^{6}$ É uma metodologia baseada na prática para modelagem eficaz de software. AM é uma coleção de práticas, guiadas por princípios e valores que podem ser aplicados por profissionais de software no dia a dia [Ambler, 2004]. 


\subsection{Arquitetura}

Com base na análise da documentação de requisitos do sistema Portal da Amazônia foi identificada sua natureza distribuída e o sistema foi classificado como cliente/servidor típico.

A partir desse modelo foram especificadas diretrizes arquiteturais e restrições para o desenvolvimento do sistema tais como: garantia de proteção de dados no sistema e validação de login; a utilização de ferramentas Free e Open Source como Hibernate e MySQL; baixos requisitos de máquina do lado do usuário para a utilização do sistema; e a realização da modelagem do sistema contemplando o requisito de expansibilidade.

A Figura 2 permite uma visualização geral da Arquitetura concebida para o sistema Portal da Amazônia, usando como base notações da UML. Pode-se destacar a utilização do padrão arquitetural de Camadas MVC (Model-View-Controller), no qual: a interface com o usuário, pacote "Páginas HTML, JSP etc", estão ligadas à camada View da arquitetura; as ações do usuário no sistema são processadas e respondidas na camada Controller (pacote "Controle"); e a camada Model é representada pelo pacote "Classes" onde se encontra o modelo de classes do sistema.

Pode-se ainda notar na Figura 2 outros padrões de projetos, soluções reutilizáveis para projetos de software que visam encapsular a reutilização de código, incorporados à arquitetura do sistema como nos pacotes "InterfaceClasseDAO", "ClasseDAO" e "BaseDAO" que implementam o padrão DAO (Data Acess Object) que atua como uma camada de acesso aos dados persistidos fornecendo serviços como salvamento e busca.

Ao lado do pacote "Persistência de Dados", que representa o banco de dados do sistema, se encontra o pacote "Mapeamento da Persistência" em que é destacado arquivos de mapeamento XML (EXtensible Markup Language), estes devido a utilização do framework Hibernate, responsável pelo mapeamento dos atributos do modelo de base de dados relacional e o modelo objeto da aplicação.

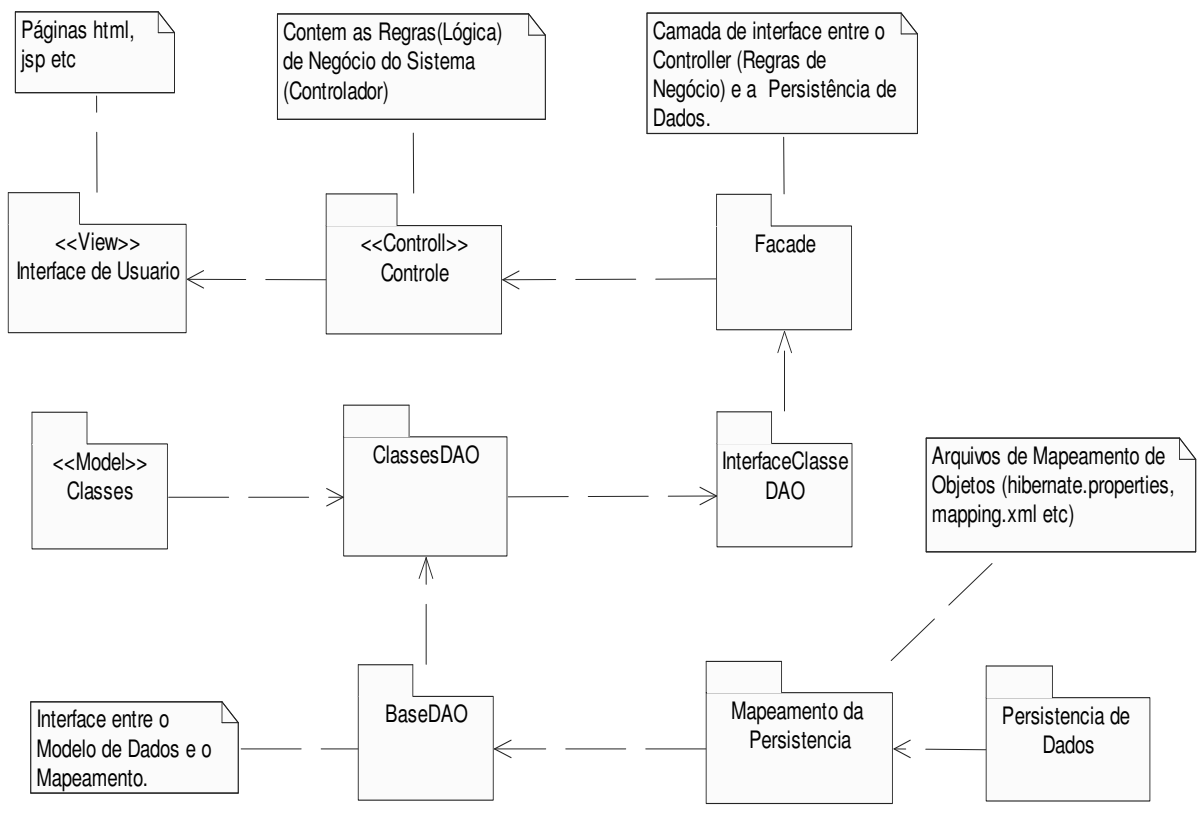

Figura 2: Hierarquia de Pacotes do Portal da Amazônia, versão 2.0. 


\subsection{Tecnologias Adotadas}

Para possibilitar o desenvolvimento do Portal da Amazônia, foi estabelecido um arcabouço de ferramentas de softwares de apoio. Conforme já discutido, a maioria dos softwares utilizados são Softwares Livres, com exceção do Rational Rose. A Tabela 2 apresenta as ferramentas de apoio usadas para a implementação do portal.

Tabela 2. Softwares de Apoio usados para o desenvolvimento

\begin{tabular}{|c|c|c|c|}
\hline Tipo & Nome & Versão & Comentário \\
\hline $\begin{array}{l}\text { Sistema } \\
\text { Operacional }\end{array}$ & $\begin{array}{l}\text { Linux } \\
\text { (Ubuntu) }\end{array}$ & 8.04 & $\begin{array}{l}\text { Escolhido por ser uma distribuição do Linux } \\
\text { de fácil instalação, além de ter se mostrado } \\
\text { estável segundo a avaliação da equipe de } \\
\text { desenvolvimento do Portal da Amazônia. }\end{array}$ \\
\hline $\begin{array}{l}\text { Linguagem de } \\
\text { Programação }\end{array}$ & Java & 6.0 & $\begin{array}{l}\text { Usada por ser uma tecnologia poderosa de } \\
\text { programação de sistemas Web, em conjunto } \\
\text { com frameworks adequados, com um grande } \\
\text { número de desenvolvedores mundialmente. }\end{array}$ \\
\hline $\begin{array}{l}\text { IDE de } \\
\text { programação }\end{array}$ & Eclipse & 3.2 & $\begin{array}{l}\text { Fornece facilidades de programação usando a } \\
\text { tecnologia Java, bem como suporte interno ao } \\
\text { CVS e ao Apache Tomcat. }\end{array}$ \\
\hline Banco de Dados & MySql & 5.0 & $\begin{array}{l}\text { Banco de dados adequado à programação de } \\
\text { sistemas } W e b, \text { largamente utilizado por } \\
\text { possuir a capacidade de gerir grandes } \\
\text { quantidades de informação eficientemente. }\end{array}$ \\
\hline $\begin{array}{l}\text { Framework Para } \\
\text { Persistência de } \\
\text { Dados }\end{array}$ & Hibernate & $3 . \mathrm{x}$ & $\begin{array}{l}\text { Facilita a troca de informação entre o sistema } \\
\text { desenvolvido usando a tecnologia Java e o } \\
\text { Banco de Dados MySql. }\end{array}$ \\
\hline $\begin{array}{l}\text { Framework Para } \\
\text { Programação Web }\end{array}$ & Struts & 1.0 & $\begin{array}{l}\text { Fornece um arcabouço de funcionalidades } \\
\text { estendíveis para sistemas Web em geral. }\end{array}$ \\
\hline $\begin{array}{l}\text { Sistema de } \\
\text { Controle de } \\
\text { Versão de } \\
\text { arquivos }\end{array}$ & $\begin{array}{l}\text { (CVS) } \\
\text { Concurrent } \\
\text { Version } \\
\text { System }\end{array}$ & 1.11 & $\begin{array}{l}\text { Escolhido por prover suporte ao } \\
\text { versionamento de arquivos e ramificações de } \\
\text { desenvolvimento.Sua usabilidade é } \\
\text { melhorada quando é integrado ao IDE } \\
\text { Eclipse. }\end{array}$ \\
\hline $\begin{array}{l}\text { Servidor de } \\
\text { Aplicações Java } \\
\text { para a Web }\end{array}$ & $\begin{array}{l}\text { Apache } \\
\text { Tomcat }\end{array}$ & 6.0 & $\begin{array}{l}\text { Fornece o contexto no qual o sistema } \\
\text { desenvolvido executa no servidor. }\end{array}$ \\
\hline $\begin{array}{l}\text { Ferramenta de } \\
\text { Modelagem }\end{array}$ & $\begin{array}{l}\text { Rational } \\
\text { Rose }\end{array}$ & 4.0 & $\begin{array}{l}\text { Ambiente de modelagem e geração de código } \\
\text { largamente utilizado. Este software, apesar de } \\
\text { ser proprietário, não representa em aumento } \\
\text { do orçamento para o Portal, pois está sob uma } \\
\text { licença acadêmica. Esta ferramenta foi usada } \\
\text { para modelagem dos diagramas técnicos. }\end{array}$ \\
\hline
\end{tabular}




\section{Resultados Obtidos, Desafios e Lições Aprendidas.}

Atualmente, o Portal da Amazônia se encontra em fase de teste pela equipe de conteúdo na rede interna da Universidade Federal do Pará (UFPA). Porém, existe uma outra versão que está em teste pela equipe de desenvolvimento, nessa versão foram feitas alterações na estrutura do banco de dados.

Durante o desenvolvimento do Portal da Amazônia, foram encontrados obstáculos com relação: (a) à rotatividade dos desenvolvedores; (b) ao processo desenvolvido que possui pequenos problemas; (c) ao modelo do fluxo de atividades; e (d) ao uso ineficiente de algumas ferramentas.

Um desafio encontrado diz respeito à rotatividade (turnover) dos integrantes da equipe de desenvolvimento. Sendo um projeto acadêmico, o desenvolvimento é feito por alunos-bolsistas, o que condiciona alta mobilidade da equipe. Surge, então, a necessidade do repasse do conhecimento para os novos integrantes, realizado por práticas de desenvolvimento, como o uso do pair programming garantindo $\mathrm{o}$ treinamento destes, além da utilização de uma documentação (requisitos, diagrama classe, diagrama de estados, diagrama de casos de uso, etc), completa o suficiente para guiar a continuidade do projeto em qualquer ponto do desenvolvimento.

O PSI é um processo prático, se adapta bem ao desenvolvimento do sistema, garantindo a flexibilidade e a rapidez necessárias para o propósito do projeto. Contudo, o processo apresenta alguns pontos fracos no que diz respeito à Gestão de Teste e no processo de Avaliação de Riscos do projeto. Uma boa solução seria o uso de softwares voltados para teste o qual facilitaria a execução de testes pelos desenvolvedores. Apesar disso, o processo do PSI propõe uma etapa de Codificação e Teste de acordo com a metodologia aplicada no XP.

O desenvolvimento do portal ocorre em paralelo à fase de teste, isto é, trata-se de um desenvolvimento orientado a teste, de acordo com a prática TDD - Test Driven Development. Portanto, o PSI não possui uma etapa formal de teste de software. Esta configuração se adequou de forma satisfatória às condições do ambiente de desenvolvimento do portal, à equipe de desenvolvimento reduzida e à curta duração das iterações que significam poucos objetivos a serem cumpridos simultaneamente, e desta forma pouco código produzido por iteração. Uma iteração é um intervalo de tempo em um processo para geração de uma versão estável de um produto. Um avanço que pode ser previsto, para otimizar essa etapa, é a adoção de uma ferramenta que dê apoio à fase de teste e integração. Atualmente, não se adota nenhuma ferramenta para automatizar as tarefas de teste permitindo uma possível agilidade natural desta disciplina no processo.

Em relação ao modelo de fluxo adotado no Portal da Amazônia, notou-se o problema da falta de fluidez do documento quando atinge a etapa de tradução, pois o documento será publicado apenas quando receber a tradução de inglês e espanhol. Uma solução para esse problema é permitir que o documento seja publicado mesmo sem suas traduções e fique indisponível nas outras línguas até a sua tradução ser efetuada. Vale mencionar que este posicionamento trata-se de uma sugestão da equipe de desenvolvimento como uma proposta de melhoria aos requisitos funcionais hoje desenvolvidos no portal.

Quanto à notificação, documentação e controle de bugs encontrados no portal, não existia nenhuma ferramenta sendo utilizada pela equipe de desenvolvimento para efetuar esse tipo de gerenciamento. Recentemente foi implementado um wiki, que está 
passando por fase de incorporação ao processo e à rotina dos desenvolvedores. A wiki é uma página $W e b$ que contém um documento no qual podem ser feitas edições por parte de vários usuários. Os resultados do gerenciamento de bugs que serão proporcionados por esta ferramenta também podem ser apontados como melhorias que serão consolidadas no desenvolvimento do portal.

O ambiente de desenvolvimento do Portal da Amazônia é um ambiente de requisitos instáveis. Há uma lista de requisitos coletados enquanto o portal encontravase em fase de concepção, porém, ao término de cada ciclo de desenvolvimento, é normal a solicitação de mudanças nestes requisitos por parte dos clientes. Este foi um dos fatores que levou à adoção de um processo com características de desenvolvimento ágil. Os possíveis obstáculos conseqüentes da recorrente mudança de requisitos acabam sendo amenizados pela constante interação com os clientes, fazendo validação do produto a cada ciclo.

Mudanças mais críticas, como alteração na lógica do fluxo de atividades, acabam gerando um pequeno atraso. Pode ser necessário concentrar a equipe no tratamento daquela mudança antes de prosseguir com as demais tarefas que haviam sido agendadas, conforme a prioridade que o cliente atribui àquela mudança de requisitos.

No contexto das práticas de comunicação constantes no processo de desenvolvimento de software, pode-se citar a comunicação entre os desenvolvedores e a comunicação entre os desenvolvedores e os clientes (equipe de conteúdo). A comunicação entre a equipe de desenvolvimento é constante e todos estão sempre cientes do andamento da iteração de cada um. Quando algum requisito novo é solicitado, toda a equipe se reúne para uma breve discussão, verificando viabilidade e prioridades. No momento que algum desenvolvedor finalizar sua iteração, os demais membros são informados imediatamente de modo informal e um e-mail é enviado para toda equipe Muiraquitã, sobre o término da iteração, relatando as modificações efetuadas e as funcionalidades concluídas.

Quando um cliente solicita uma modificação/adição nos requisitos, a solicitação é feita de modo ágil devido ao fato dos clientes e desenvolvedores estarem na mesma instituição (Informam). Isso faz com que o cliente tenha uma resposta rápida dos impactos que o seu pedido causará. Outra vantagem da comunicação constante com os clientes é a facilidade de realizar uma reunião entre os desenvolvedores e clientes para avaliação do andamento do projeto.

\section{Conclusões}

Este artigo abordou o processo de desenvolvimento do projeto "Portal da Amazônia: navegando entre o rio e a floresta", um portal de conteúdo que vem para contemplar a demanda de agente acumulador e divulgador de conteúdos culturais, técnicos e científicos da Amazônia e almeja se tornar um ponto de referência para buscas de conteúdos relacionados à Amazônia. O portal se vale de aspectos como relevância e qualidade de conteúdo, internacionalização da informação e colaboração para alcançar esse objetivo.

Foram discutidos alguns pontos importantes no que se refere às dificuldades enfrentadas, com suas possíveis resoluções, algumas delas implementadas. E a partir desta análise, podem-se identificar possíveis trabalhos a serem desenvolvidos:

- Análise da Usabilidade do Produto; 
- Aplicação de Padrões de Projeto no Produto;

- Análise de Desempenho do Produto;

- Análise Crítica da Segurança no Produto.

Segundo Barbosa, em [Barbosa, 2008], são propostos os seguintes refinamentos no processo de software PSI:

- Reformular a formalização do Processo de Software Informam em um documento que explicite claramente as responsabilidades dos papéis funcionais de seus agentes, com a discriminação da realização de suas atividades. Neste aspecto, é necessária também a especificação de modelos de artefatos de software e a delineação dos fluxos de trabalho com a relação de seus respectivos componentes;

- Implantar uma equipe de Qualidade de Software no Informam com o objetivo de manter as práticas de software já existentes e realizar a contínua avaliação da adequação de qualidade das instâncias dos processos e das Melhorias de Processo de Software.

Trabalhos futuros no que concerne a ampliações da formalização do processo, refinamentos no processo e na arquitetura, e atualizações das necessidades funcionais e não funcionais do produto serão especificados à medida que forem concluídas as metas (demandas) de desenvolvimento dos clientes, pela equipe de desenvolvimento do Portal da Amazônia, a fim de mostrar o avanço gradativo que tem sido feito no projeto e na produção e maturidade da fábrica de software que este projeto nutriu.

\section{Referências}

Ambler, S. W. (2004) Modelagem Ágil: Práticas eficazes para a programação eXtrema e o Processo Unificado, Bookman, 2.ed., Porto Alegre.

Barbosa, E. C. "Auditoria de Qualidade do Processo de Software Informam (PSI)". Belém (PA): UFPA/CBCC, 2008. Trabalho de Conclusão de Curso.

Free Software Foundation. (2008) "What is free software", Disponível em http://www.fsf.org/about/what-is-free-software, Acessado em 06/12/2008.

IBM Rational Software. (2008) "Rational Unified Process", Disponível em http://www.wthreex.com/rup/index.htm, Acessado em 06/12/2008.

Lemos, A. de M., Prado Junior, A. C., Guerreiro, C. M., Barbosa, E. C., Pereira, L. P., Gonçalves, M. K. (2006) "Portal da Amazônia: Concentrando informações regionais com ferramentas livres", In: XX Semana Paraense de Informática e Telecomunicações, Belém-PA.

O’brien, J. A. (2004) Sistemas de Informação e as decisões gerenciais na era da Internet, Saraiva, 2. ed., São Paulo.

Prado Junior, A. C. (2004) "Portal da Amazônia: navegando entre o rio e a floresta. Análise e projeto para uma nova versão". CETCCEN6/PROINT, 2004. Belém-PA.

(2006) "Portal da Amazônia: navegando entre o rio e a floresta. Implementação e ampliação da versão desenvolvida no CETCCEN6" 2CCEN0110014/PROINT, 2006. Belém-PA.

Pressman, R. S. (2004) Engenharia de Software, McGraw-Hill, 6 ed., Rio de Janeiro. 